\title{
Alpha-beta chimeric polypeptide molecular brushes display potent activity against superbugs-methicillin resistant Staphylococcus aureus
}

\author{
Danfeng Zhang, Yuxin Qian, Si Zhang, Pengcheng Ma, Qiang Zhang, Ning Shao, Fan Qi, \\ Jiayang Xie, Chengzhi Dai, Ruiyi Zhou, Zhongqian Qiao, Wenjing Zhang, Sheng Chen and \\ Runhui Liu ${ }^{*}$
}

Staphylococcus aureus (S. aureus) are frequently encountered for both nosocomial infections and community acquired infections, with special concerns on the quick emergence of methicillin resistant $S$. aureus (MRSA) $[1,2]$. Antibiotics are used extensively to treat these infections [2]. However, antimicrobial resistance has been a tremendous challenge against current antibiotic and calls for urgent actions to explore novel antimicrobial agents that are active against MRSA and are less susceptible to antimicrobial resistance than do conventional antibiotics [3-13]. Encouraged by the low propensity for microbes to develop antimicrobial resistance, host defense peptides (HDPs) and their synthetic mimics were actively studied [3,4,14-34]. Although peptidyl mimics of HDP have variable structures, many of them involved multiple copies of $\alpha$-L-lysine to introduce into the molecules positive charges that were critical for the antimicrobial activity $[35,36]$.

Polymer brushes have been explored not only for their interesting morphology [37-49], but also for their unique functions compared to linear polymers [50-64]. In this study, we designed alpha-beta chimeric polypeptide molecular brush $(\alpha / \beta \mathrm{CPMB})$ with $\beta$-polypeptide or poly- $\beta$ amino acid (P $\beta A A)$ as the backbone and poly- $\alpha$-L-lysine $(\mathrm{P} \alpha \mathrm{LL})$ grafting from the backbone for antimicrobial studies. We chose $\beta$-polypeptide as the backbone for the antimicrobial molecular brush because $\beta$-polypeptides are biocompatible and can be easily prepared via anionic ring opening polymerization to provide diverse structures and functions [22-25,65-67]. In addition, the $\beta$-polypeptide backbone can easily introduce amine groups as desired activation sites for graft from polymerization of $a$-L-LysNCA (a-L-lysine $\mathrm{N}$-carboxyanhydride) to incorporate multiple poly- $\alpha$-L-lysine sidechains with adjustable density [68]. We hypothesized that above $\alpha / \beta$ CPMB have highly packed poly- $\alpha$-L-lysine sidechains to exert multivalent interactions with bacteria and achieve strong antimicrobial activity, which was supported by our recent study on end tethered $\beta$-polypeptides [69]. This design also implies that the $\alpha / \beta$ CPMBs may not be biodegradable very easily due to the steric hindrance of sidechain polylysine, a result we pursue to prolong the antimicrobial activity of these polymer brushes. To the best of our knowledge, this is the first demonstration of coupling two ring-opening polymerization (ROP) systems, the $\beta$ lactam ROP and the NCA ROP, in generating alpha-beta chimeric polypeptide molecular brushes and evaluating on their antimicrobial activities.

The backbone of the $\alpha / \beta \mathrm{CPMB}$, a $\beta$-polypeptide or poly- $\beta$-amino acid (P $\beta A A)$, was synthesized from a base catalyzed anionic ROP of 1:1 mixture of two $\beta$-lactams by following a previously reported method, with one $\beta$-lactam having a hydrophobic sidechain and the other $\beta$ lactam having an amine-containing sidechain $[25,66]$. The pendent amine groups of the $\beta$-polypeptide backbone then serve as activation sites for the ROP of $\alpha$-L-Lys-NCA to provide the $\alpha / \beta$ CPMB as described in Fig. 1 . The $\beta$ polypeptide backbone was synthesized with narrow polydispersity index (PDI) of 1.20 as summarized in Table 1. The average degree of polymerization (DP) of this $\beta$-polypeptide backbone was found to be 18 using gel permeation chromatography (GPC) characterization. In

State Key Laboratory of Bioreactor Engineering, Key Laboratory for Ultrafine Materials of Ministry of Education, Research Center for Biomedical Materials of Ministry of Education, East China University of Science and Technology, Shanghai 200237, China

* Corresponding author (email: Rliu@ecust.edu.cn) 

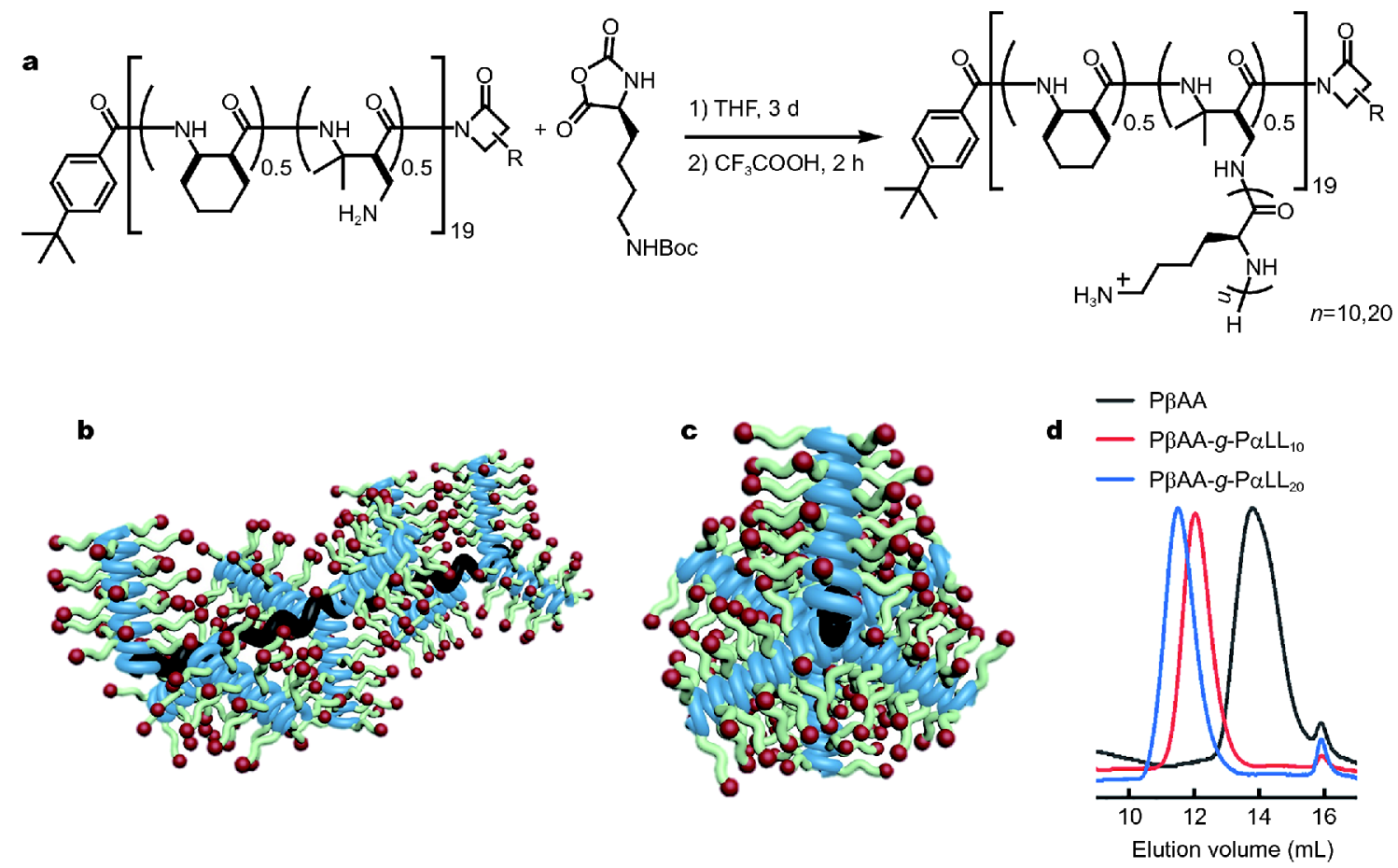

Figure 1 Synthesis of $\alpha / \beta$ CPMBs. (a) Synthetic route of $\alpha / \beta$ CPMBs; (b) sideview of $\alpha / \beta$ CPMBs carton; (c) $3 \mathrm{D}$ view of the $\alpha / \beta$ CPMBs carton; (d) GPC traces of P $\beta$ AA backbone and $\alpha / \beta$ CPMB at the amine protected stage.

Table 1 NMR and GPC characterizations of $\alpha / \beta$ CPMBs

\begin{tabular}{|c|c|c|c|c|}
\hline \multirow{2}{*}{ Polymer } & \multirow{2}{*}{$\frac{\text { NMR }}{\text { DP }}$} & \multicolumn{3}{|c|}{ GPC characterization ${ }^{a}$} \\
\hline & & $M_{\mathrm{n}}(\mathrm{kDa})$ & PDI & DP \\
\hline $\mathrm{P} \beta \mathrm{AA}$ & 19 & 3.3 & 1.20 & 18 \\
\hline $\mathrm{P} \beta \mathrm{AA}-g-\mathrm{P} \alpha \mathrm{LL}_{10}$ & 17 & 33.4 & 1.28 & 13 \\
\hline $\mathrm{P} \beta A A-g-\mathrm{P} \alpha L_{20}$ & 25 & 48.1 & 1.24 & 20 \\
\hline $\mathrm{PaLL}_{20}$ & 22 & 8.9 & 1.24 & 35 \\
\hline
\end{tabular}

a) GPC characterization on polypeptide at the amine protected stage using DMF as the mobile phase at a flow rate of $1 \mathrm{~mL} \mathrm{~min}^{-1}$.

order to further attach poly- $\alpha$-L-lysine onto to the $\beta$ polypeptide backbone and generate the $\alpha / \beta$ CPMBs, we choose the extensively used NCA polymerization. By using the backbone pendent amine groups as the initiation points, the poly- $\alpha$-L-lysine chains were grafted from the backbone. Two $\alpha / \beta$ CPMBs, P $\beta A A-g-\mathrm{PLLL}_{10}$ and $\mathrm{P} \beta A \mathrm{~A}-g-\mathrm{P} \alpha \mathrm{LL}_{20}$, were synthesized to have different length of sidechain poly- $\alpha$-L-lysine, with DP designed to be 10 and 20 respectively. The GPC characterization clearly indicated increase of $M_{\mathrm{n}}$ from the $\beta$-polypeptide backbone $(\mathrm{P} \beta \mathrm{AA})$ at $3.3 \mathrm{kDa}$ to the final $\alpha / \beta$ CPMBs $(\mathrm{P} \beta \mathrm{AA}$ $g$-P $\alpha L_{10}$ and $\left.\mathrm{P} \beta A A-g-\mathrm{P} \alpha L_{20}\right)$ at about 33.4 and $48.1 \mathrm{kDa}$ and a narrow PDI at 1.28 and 1.24 , respectively. DP of the $\beta$-polypeptide backbone and final $\alpha / \beta$ CPMBs were also confirmed using nuclear magnetic resonance (NMR) spectra and the results were comparable to those obtained from GPC characterization. The diameters of $\alpha / \beta$ CPMBs were measured by dynamic light scattering (DLS) to get an average particle size of $8.35 \pm 2.02 \mathrm{~nm}$ for $\mathrm{P} \beta A A-g$ $\mathrm{PaLL}_{10}$ and $17.22 \pm 4.14 \mathrm{~nm}$ for $\mathrm{P} \beta A A-g-\mathrm{PaLL}_{20}$ in a solution of phosphate buffered saline (PBS) at $0.5 \mathrm{mg} \mathrm{mL}^{-1}$ of polymer (Fig. S1).

The prepared $\alpha / \beta$ CPMBs were compared with antibiotic vancomycin and a representative HDP magainin II, and their antibacterial activities were evaluated against five strains of MRSA as summarized in Table 2. The antimicrobial activities of $\mathrm{P} \beta A A$ against $S$. aureus were already reported in precedent literature, and this data was not included here because P $\beta A A$ was used as the backbone in the polymer brushes without showing antimicrobial activities $[70,71]$. Both $\alpha / \beta$ CPMBs displayed potent antibacterial activity against all tested strains of MRSA. The sidechain poly- $\alpha$-L-lysine grafted $\alpha / \beta$ CPMBs are not only bacterial static but indeed bactericidal with minimum bactericidal concentration $(\mathrm{MBC})$ equal to minimum inhibitory concentration (MIC) value at 0.38 and $0.26 \mu \mathrm{mol} \mathrm{L}^{-1}$ respectively for $\mathrm{P} \beta \mathrm{AA}-g-\mathrm{PaLL}_{10}$ and $\mathrm{P} \beta \mathrm{AA}-g-\mathrm{P} \alpha L_{20}$. Both $\alpha / \beta$ CPMBs performed even better than the antibiotic vancomycin that displayed a MBC at 
Table 2 Antibacterial activity of $\alpha / \beta$ CPMBs against multiple strains of MRSA

\begin{tabular}{|c|c|c|c|c|c|}
\hline \multirow{2}{*}{ Antimicrobial compound } & \multicolumn{5}{|c|}{$\operatorname{MIC}(\mathrm{MBC})^{\mathrm{a}} \mu \mathrm{mol} \mathrm{L}^{-1}$} \\
\hline & USA300 & USA300 Lac & Newman & Mu50 & USA400 \\
\hline $\mathrm{P} \beta \mathrm{AA}-g-\mathrm{P} \alpha \mathrm{LL}_{10}$ & $0.38(0.38)$ & $0.38(0.38)$ & $0.38(0.38)$ & $0.38(0.38)$ & $0.38(0.38)$ \\
\hline $\mathrm{P} \beta \mathrm{AA}-g-\mathrm{P} \alpha \mathrm{LL}_{20}$ & $0.26(0.26)$ & $0.26(0.26)$ & $0.26(0.26)$ & $0.26(0.26)$ & $0.26(0.26)$ \\
\hline $\mathrm{PaLL}_{20}$ & $1.44(1.44)$ & $1.44(1.44)$ & $1.44(1.44)$ & $1.44(1.44)$ & $1.44(1.44)$ \\
\hline Vancomycin & $0.26(0.52)$ & $0.52(0.52)$ & $0.52(0.52)$ & $0.26(0.52)$ & $0.26(0.52)$ \\
\hline Magainin II & $\mathrm{ND}^{\mathrm{b}}$ & $\mathrm{ND}^{\mathrm{b}}$ & $\mathrm{ND}^{\mathrm{b}}$ & $\mathrm{ND}^{\mathrm{b}}$ & $\mathrm{ND}^{\mathrm{b}}$ \\
\hline
\end{tabular}

a) MIC (minimum inhibitory concentration) is the minimum compound concentration to inhibit bacteria growth; MBC (minimum bactericidal concentration) is the minimum compound concentration to kill bacteria; b) ND means activity is not detected even under the highest compound concentration at $77.8 \mu \mathrm{mol} \mathrm{L}^{-1}$.
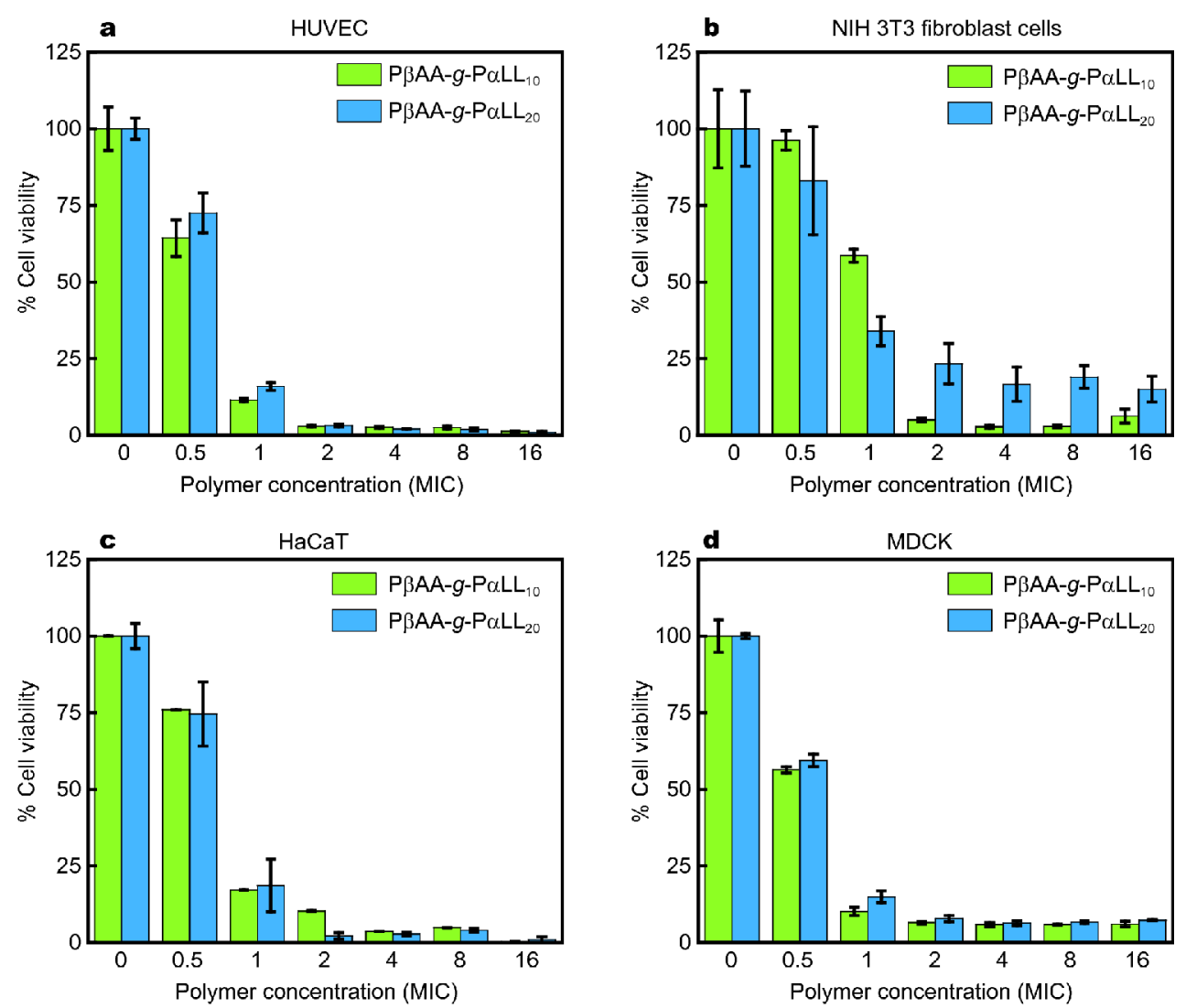

Figure 2 Cytotoxicity of $\alpha / \beta$ CPMBs toward (a) HUVEC (ATCC PCS-100-010), (b) NIH 3T3 fibroblast cells (ATCC CRL-1658), (c) HaCaT (BNCC342026) and (d) MDCK (NBL-2, ATCC CCL-34). The concentrations of P $\beta A A-g-P_{2 L L}$ and P $\beta A A-g$-PaLL 20 used for cytotoxicity experiments are related to their MIC value against $S$. aureus USA300 as shown in Table 2. The value of MIC is $0.38 \mu \mathrm{mol} \mathrm{L}^{-1}$ for P $\beta \mathrm{AA}_{-}$-PaLL $\mathrm{P}_{10}$ and $0.26 \mu \mathrm{mol} \mathrm{L}^{-1}$ for P $\beta A A-g-\mathrm{PaLL}_{20}$

$0.52 \mu \mathrm{mol} \mathrm{L}{ }^{-1}$ against all strains of MRSA. We also compared the polymer brushes with single chain poly- $\alpha-$ L-lysine $\left(\mathrm{PaLL}_{20}\right)$ and found the polymer brush P $\beta A A-g$ $\mathrm{PaLL}_{20}$ was 5.5 fold more active than the $\mathrm{PaLL}_{20}$ and has similar cytotoxicity compared to corresponding $\mathrm{PaLL}_{20}$ (Fig. S2). All these results imply that the potent antibacterial activity of $\alpha / \beta$ CPMBs (P $\beta A A-g-\mathrm{PLL}_{10}$ and
P $\left.\beta A A-g-P \alpha L L_{20}\right)$ derived from the molecular design of multiple sidechain grafted poly- $\alpha$-L-lysine that possess multivalent interactions with bacteria. The representative HDP magainin II, as another control within this study, has no activity at all even at the highest concentration $\left(77.8 \mu \mathrm{mol} \mathrm{L}^{-1}\right)$ within the test. We also did cytotoxicity study on these polymers using four different mammalian 


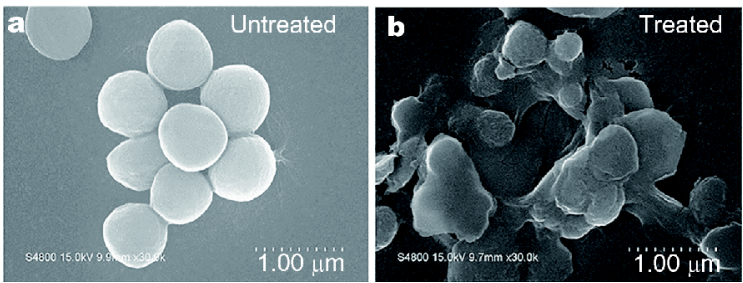

Figure 3 SEM characterization of MRSA cell morphology change after bacteria incubation with the $\alpha / \beta$ CPMB. (a) MRSA cells without antimicrobial treatment as control and (b) MRSA cells incubated with $\alpha / \beta$ CPMB for $20 \mathrm{~min}$.

cells and found that these two polymer brushes have similar toxicity for most of the cell types (Fig. 2). As is well known, polylysine itself is generally toxic to mammalian cells due to the high intensity of positive charges along the polymer chain; therefore, the cytotoxicity of these polymer brushes likely comes from the polylysine sidechains.

In order to understand how these $\alpha / \beta$ CPMBs interact with bacteria, the polymer molecular brush was incubated with MRSA cells for $20 \mathrm{~min}$ and then the bacteria cells were characterized by scanning electron microscopy (SEM). As shown in Fig. 3, bacteria from the polymerfree control sample have intact and smooth cell membrane. However, the bacteria after incubation with $\alpha / \beta$ CPMBs have obviously irregular cell morphology and defects of cell membrane. These results imply that the $\alpha / \beta$ CPMB kill $S$. aureus quickly by disrupting bacteria cell membrane using its multiple sidechain poly- $\alpha$-L-lysine that is generally considered as HDP mimics. Similar observations have been reported for HDP and their mimics because these types of antimicrobial agents target cell membrane to have antibacterial activity [72].

In conclusion, we demonstrated a perfect match of two ROP systems, the $\beta$-lactam ROP and the NCA ROP, in generating alpha-beta chimeric poly-peptide molecular brushes $(\alpha / \beta$ CPMBs) using $\beta$-polypeptide as the backbone and grafted poly- $\alpha-\mathrm{L}$-lysine as the sidechains. These $\alpha / \beta$ CPMBs demonstrated potent in vitro bactericidal activities, even better than vancomycin, against multiple strains of MRSA superbugs. The easily tunable polymerization of two ROP systems, the diversified structure of both $\beta$-lactam and NCA, and the potent superbug killing activity altogether imply great potential of the $\alpha / \beta$ CPMBs in antimicrobial applications.

\section{Received 17 August 2018; accepted 5 September 2018;} published online 21 September 2018

1 Taubes G. The bacteria fight back. Science, 2008, 321: 356-361

2 Purrello SM, Garau J, Giamarellos E, et al. Methicillin-resistant
Staphylococcus aureus infections: A review of the currently available treatment options. J Glob Antimicrobial Resistance, 2016, 7: 178-186

3 Hancock REW, Sahl HG. Antimicrobial and host-defense peptides as new anti-infective therapeutic strategies. Nat Biotechnol, 2006, 24: $1551-1557$

4 Boman HG. Antibacterial peptides: Basic facts and emerging concepts. J Intern Med, 2003, 254: 197-215

5 Zasloff M. Antimicrobial peptides of multicellular organisms. Nature, 2002, 415: 389-395

6 Nederberg F, Zhang Y, Tan JPK, et al. Biodegradable nanostructures with selective lysis of microbial membranes. Nat Chem, 2011, 3: 409-414

7 Bai $\mathrm{H}$, Yuan $\mathrm{H}$, Nie C, et al. A supramolecular antibiotic switch for antibacterial regulation. Angew Chem Int Ed, 2015, 54: 1320813213

8 Liu K, Liu Y, Yao Y, et al. Supramolecular photosensitizers with enhanced antibacterial efficiency. Angew Chem Int Ed, 2013, 52: 8285-8289

$9 \mathrm{Hu} \mathrm{D}, \mathrm{Li} \mathrm{H}$, Wang B, et al. Surface-adaptive gold nanoparticles with effective adherence and enhanced photothermal ablation of methicillin-resistant Staphylococcus aureus biofilm. ACS Nano, 2017, 11: 9330-9339

10 Huang Y, Ding X, Qi Y, et al. Reduction-responsive multifunctional hyperbranched polyaminoglycosides with excellent antibacterial activity, biocompatibility and gene transfection capability. Biomaterials, 2016, 106: 134-143

11 Wei T, Tang Z, Yu Q, et al. Smart antibacterial surfaces with switchable bacteria-killing and bacteria-releasing capabilities. ACS Appl Mater Interfaces, 2017, 9: 37511-37523

12 Hancock REW, Haney EF, Gill EE. The immunology of host defence peptides: Beyond antimicrobial activity. Nat Rev Immunol, 2016, 16: 321-334

13 Yang Y, He P, Wang Y, et al. Supramolecular radical anions triggered by bacteria in situ for selective photothermal therapy. Angew Chem Int Ed, 2017, 56: 16239-16242

14 Porter EA, Wang X, Lee HS, et al. Non-haemolytic $\beta$-amino-acid oligomers. Nature, 2000, 404: 565

15 Kuroda K, DeGrado WF. Amphiphilic polymethacrylate derivatives as antimicrobial agents. J Am Chem Soc, 2005, 127: 41284129

16 Lienkamp K, Madkour AE, Musante A, et al. Antimicrobial polymers prepared by romp with unprecedented selectivity: A molecular construction kit approach. J Am Chem Soc, 2008, 130: 9836-9843

17 Song A, Walker SG, Parker KA, et al. Antibacterial studies of cationic polymers with alternating, random, and uniform backbones. ACS Chem Biol, 2011, 6: 590-599

18 Palermo EF, Sovadinova I, Kuroda K. Structural determinants of antimicrobial activity and biocompatibility in membrane-disrupting methacrylamide random copolymers. Biomacromolecules, 2009, 10: 3098-3107

19 Jiang Y, Yang X, Zhu R, et al. Acid-activated antimicrobial random copolymers: A mechanism-guided design of antimicrobial peptide mimics. Macromolecules, 2013, 46: 3959-3964

20 Xiong M, Lee MW, Mansbach RA, et al. Helical antimicrobial polypeptides with radial amphiphilicity. Proc Natl Acad Sci USA, 2015, 112: 13155-13160

21 Qian Y, Zhang D, Wu Y, et al. The design,synthesis and biological activity study of nylon-3 polymers as mimics of host defense 
peptides. Acta Polym Sin, 2016, 1300-1311

22 Liu R, Suárez JM, Weisblum B, et al. Synthetic polymers active against Clostridium difficile vegetative cell growth and spore outgrowth. J Am Chem Soc, 2014, 136: 14498-14504

23 Liu R, Chen X, Hayouka Z, et al. Nylon-3 polymers with selective antifungal activity. J Am Chem Soc, 2013, 135: 5270-5273

24 Liu R, Chen X, Falk SP, et al. Nylon-3 polymers active against drug-resistant Candida albicans biofilms. J Am Chem Soc, 2015, 137: 2183-2186

25 Liu R, Chen X, Chakraborty S, et al. Tuning the biological activity profile of antibacterial polymers via subunit substitution pattern. J Am Chem Soc, 2014, 136: 4410-4418

26 Tew GN, Scott RW, Klein ML, et al. De novo design of antimicrobial polymers, foldamers, and small molecules: From discovery to practical applications. Acc Chem Res, 2010, 43: 30-39

27 Li P, Zhou C, Rayatpisheh S, et al. Cationic peptidopolysaccharides show excellent broad-spectrum antimicrobial activities and high selectivity. Adv Mater, 2012, 24: 4130-4137

28 Niu Y, Padhee S, Wu H, et al. Identification of $\gamma$-AApeptides with potent and broad-spectrum antimicrobial activity. Chem Commun, 2011, 47: 12197

29 Niu Y, Padhee S, Wu H, et al. Lipo- $\gamma$-AApeptides as a new class of potent and broad-spectrum antimicrobial agents. J Med Chem, 2012, 55: 4003-4009

30 Padhee S, Hu Y, Niu Y, et al. Non-hemolytic a-AApeptides as antimicrobial peptidomimetics. Chem Commun, 2011, 47: 9729

31 Yarlagadda V, Akkapeddi P, Manjunath GB, et al. Membrane active vancomycin analogues: A strategy to combat bacterial resistance. J Med Chem, 2014, 57: 4558-4568

32 Yarlagadda V, Samaddar S, Paramanandham K, et al. Membrane disruption and enhanced inhibition of cell-wall biosynthesis: A synergistic approach to tackle vancomycin-resistant bacteria. Angew Chem Int Ed, 2015, 54: 13644-13649

33 Choi H, Chakraborty S, Liu R, et al. Single-cell, time-resolved antimicrobial effects of a highly cationic, random nylon-3 copolymer on live Escherichia coli. ACS Chem Biol, 2016, 11: 113-120

34 Ding X, Duan S, Ding X, et al. Versatile antibacterial materials: An emerging arsenal for combatting bacterial pathogens. Adv Funct Mater, 2018, 362: 1802140

35 Su Y, Tian L, Yu M, et al. Cationic peptidopolysaccharides synthesized by 'click' chemistry with enhanced broad-spectrum antimicrobial activities. Polym Chem, 2017, 8: 3788-3800

36 Pranantyo D, Xu LQ, Hou Z, et al. Increasing bacterial affinity and cytocompatibility with four-arm star glycopolymers and antimicrobial a-polylysine. Polym Chem, 2017, 8: 3364-3373

37 Lu H, Wang J, Lin Y, et al. One-pot synthesis of brush-like polymers via integrated ring-opening metathesis polymerization and polymerization of amino acid $\mathrm{N}$-carboxyanhydrides. J Am Chem Soc, 2009, 131: 13582-13583

38 Wang J, Lu H, Ren Y, et al. Interrupted helical structure of grafted polypeptides in brush-like macromolecules. Macromolecules, 2015, 44: 8699-8708

39 Meereboer NL, Terzić I, Saidi S, et al. Two-dimensional controlled syntheses of polypeptide molecular brushes via $\mathrm{N}$-carboxyanhydride ring-opening polymerization and ring-opening metathesis polymerization. ACS Macro Lett, 2017, 6: 1031-1035

40 Beers KL, Gaynor SG, Matyjaszewski K, et al. The synthesis of densely grafted copolymers by atom transfer radical polymerization. Macromolecules, 1998, 31: 9413-9415

41 Cheng G, Böker A, Zhang M, et al. Amphiphilic cylindrical core -shell brushes via a "grafting from" process using atrp. Macromolecules, 2001, 34: 6883-6888

42 Gerle M, Fischer K, Roos S, et al. Main chain conformation and anomalous elution behavior of cylindrical brushes as revealed by GPC/MALLS, light scattering, and SFM. Macromolecules, 1999, 32: 2629-2637

43 Li Z, Ma J, Cheng C, et al. Synthesis of hetero-grafted amphiphilic diblock molecular brushes and their self-assembly in aqueous medium. Macromolecules, 2010, 43: 1182-1184

44 Müllner M, Dodds SJ, Nguyen TH, et al. Size and rigidity of cylindrical polymer brushes dictate long circulating properties in vivo. ACS Nano, 2015, 9: 1294-1304

45 Neugebauer D, Sumerlin BS, Matyjaszewski K, et al. How dense are cylindrical brushes grafted from a multifunctional macroinitiator? Polymer, 2004, 45: 8173-8179

46 Runge MB, Bowden NB. Synthesis of high molecular weight comb block copolymers and their assembly into ordered morphologies in the solid state. J Am Chem Soc, 2007, 129: 10551-10560

47 Xia Y, Kornfield JA, Grubbs RH. Efficient synthesis of narrowly dispersed brush polymers via living ring-opening metathesis polymerization of macromonomers. Macromolecules, 2009, 42: 3761-3766

48 Zheng G, Pan C. Reversible addition-fragmentation transfer polymerization in nanosized micelles formed in situ. Macromolecules, 2006, 39: 95-102

49 Xia Y, Olsen BD, Kornfield JA, et al. Efficient synthesis of narrowly dispersed brush copolymers and study of their assemblies: The importance of side chain arrangement. J Am Chem Soc, 2009, 131: 18525-18532

50 Zhang Y, Yin Q, Lu H, et al. Peg-polypeptide dual brush block copolymers: Synthesis and application in nanoparticle surface pegylation. ACS Macro Lett, 2013, 2: 809-813

51 Gao Q, Yu M, Su Y, et al. Rationally designed dual functional block copolymers for bottlebrush-like coatings: In vitro and in vivo antimicrobial, antibiofilm, and antifouling properties. Acta Biomater, 2017, 51: 112-124

52 Verduzco R, Li X, Pesek SL, et al. Structure, function, self-assembly, and applications of bottlebrush copolymers. Chem Soc Rev, 2015, 44: 2405-2420

53 Lu X, Tran TH, Jia F, et al. Providing oligonucleotides with steric selectivity by brush-polymer-assisted compaction. J Am Chem Soc, 2015, 137: 12466-12469

54 Gao AX, Liao L, Johnson JA. Synthesis of acid-labile peg and pegdoxorubicin-conjugate nanoparticles via brush-first romp. ACS Macro Lett, 2014, 3: 854-857

55 Gao H, Matyjaszewski K. Synthesis of molecular brushes by "grafting onto" method: combination of ATRP and click reactions. J Am Chem Soc, 2007, 129: 6633-6639

56 Guo J, Hong H, Chen G, et al. Theranostic unimolecular micelles based on brush-shaped amphiphilic block copolymers for tumortargeted drug delivery and positron emission tomography imaging. ACS Appl Mater Interfaces, 2014, 6: 21769-21779

57 Hörtz C, Birke A, Kaps L, et al. Cylindrical brush polymers with polysarcosine side chains: A novel biocompatible carrier for biomedical applications. Macromolecules, 2015, 48: 2074-2086

58 Jin X, Sun P, Tong G, et al. Star polymer-based unimolecular micelles and their application in bio-imaging and diagnosis. Biomaterials, 2018, 178: 738-750

59 Li H, Liu H, Nie T, et al. Molecular bottlebrush as a unimolecular vehicle with tunable shape for photothermal cancer therapy. Bio- 
materials, 2018, 178: 620-629

60 Liao L, Liu J, Dreaden EC, et al. A convergent synthetic platform for single-nanoparticle combination cancer therapy: Ratiometric loading and controlled release of cisplatin, doxorubicin, and camptothecin. J Am Chem Soc, 2014, 136: 5896-5899

61 Müllner M, Mehta D, Nowell CJ, et al. Passive tumour targeting and extravasation of cylindrical polymer brushes in mouse xenografts. Chem Commun, 2016, 52: 9121-9124

62 Sowers MA, McCombs JR, Wang Y, et al. Redox-responsive branched-bottlebrush polymers for in vivo MRI and fluorescence imaging. Nat Commun, 2014, 5: 5460

63 von Erlach T, Zwicker S, Pidhatika B, et al. Formation and characterization of DNA-polymer-condensates based on poly(2-methyl-2-oxazoline) grafted poly(l-lysine) for non-viral delivery of therapeutic DNA. Biomaterials, 2011, 32: 5291-5303

64 Zeng X, Wang L, Liu D, et al. Poly(l-lysine)-based cylindrical copolypeptide brushes as potential drug and gene carriers. Colloid Polym Sci, 2016, 294: 1909-1920

65 Liu R, Masters KS, Gellman SH. Polymer chain length effects on fibroblast attachment on nylon-3-modified surfaces. Biomacromolecules, 2012, 13: 1100-1105

66 Liu R, Chen X, Gellman SH, et al. Nylon-3 polymers that enable selective culture of endothelial cells. J Am Chem Soc, 2013, 135: 16296-16299

67 Liu R, Chen X, Falk SP, et al. Structure-activity relationships among antifungal nylon-3 polymers: identification of materials active against drug-resistant strains of Candida albicans. J Am Chem Soc, 2014, 136: 4333-4342

68 Hou Y, Wang Y, Wang R, et al. Harnessing phosphato-platinum bonding induced supramolecular assembly for systemic cisplatin delivery. ACS Appl Mater Interfaces, 2017, 9: 17757-17768

69 Qian Y, Qi F, Chen Q, et al. Surface modified with a host defense peptide-mimicking B-peptide polymer kills bacteria on contact with high efficacy. ACS Appl Mater Interfaces, 2018, 10: 1539515400

70 Chakraborty S, Liu R, Hayouka Z, et al. Ternary nylon-3 copoly- mers as host-defense peptide mimics: Beyond hydrophobic and cationic subunits. J Am Chem Soc, 2014, 136: 14530-14535

71 Zhang D, Zhang S, Ma P, et al. Synthetic peptidyl polymer displaying potent activity against gram positive bacteria. J Funct Polym, 2018, DOI: 10.14133/j.cnki.1008-9357.20180410001

72 Hovakeemian SG, Liu R, Gellman SH, et al. Correlating antimicrobial activity and model membrane leakage induced by nylon3 polymers and detergents. Soft Matter, 2015, 11: 6840-6851

Acknowledgements This research was supported by the National Natural Science Foundation of China (21574038 and 21774031), the National Natural Science Foundation of China for Innovative Research Groups (51621002), the National Key Research and Development Program of China (2016YFC1100401), the Natural Science Foundation of Shanghai (18ZR1410300), the "Eastern Scholar Professorship" from Shanghai local government (TP2014034), the national special fund for State Key Laboratory of Bioreactor Engineering (2060204), the 1000 Talent Young Scholar program in China, 111 project (B14018), and the program for professor of special appointment at ECUST. The authors thank Research Center of Analysis and Test of East China University of Science and Technology for the help on the characterization. We also thank Prof. Hua Lv and Prof. Lichen Yin for valuable discussions on NCA synthesis and purification.

Author contributions Liu R designed and directed the project; Zhang D, Ma P synthesized the samples; Zhang D, Zhang Q and Qiao Z did the characterization of samples; Zhang D, Zhang S, Shao N, Qian Y, Xie J, Dai C, Qi F, Zhang W and Cheng S and Zhou R performed the biological experiments; Liu R, Zhang D analyzed the data; Liu R, Zhang D and Zhang $S$ wrote the paper. All authors reviewed the manuscript.

Conflict of interest The authors declare that they have no conflict of interest.

Supplementary information Experimental details and supporting data are available in the online version of the paper. 


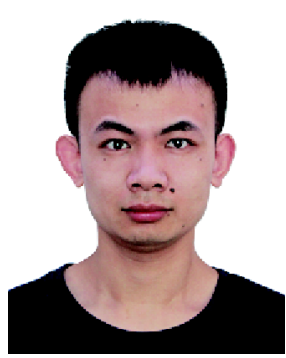

Danfeng Zhang was born in 1992. He received his BSc degree majored in material science and engineering from East China University of Science and Technology (ECUST) in 2018. His research interest is polymeric antimicrobial material.

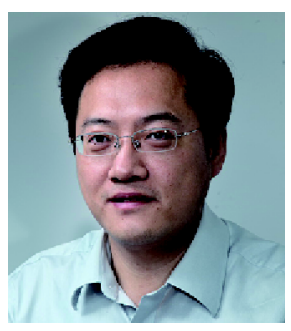

Runhui Liu obtained BSc in pharmaceutical engineering in 2001 at East China University of Science \& Technology. He obtained PhD in Organic Chemistry 2009 at Purdue University. Afterward, he worked as a postdoc at California Institute of Technology and University of Wisconsin-Madison. In 2014, he took a professor position in the School of Materials Science and Engineering at ECUST. His current research focuses on polypeptide polymers for antimicrobial and tissue engineering applications.

\section{具有高效抗MRSA活性的Alpha-Beta杂化多肽聚合物分子刷}

张丹丰, 钱宇芯, 张思, 马鹏程, 张强, 郡宁, 齐凡, 谢佳洋, 代承志, 周睿毅, 乔忠乾, 张雯静, 陈胜, 刘润辉 ${ }^{*}$

摘要 近年来, 以耐甲氧西林金黄色葡萄球菌(MRSA)为代表的“超级细菌”不断被发现和扩散, 已经严重威胁人类健康, 因此, 研制新型、 高效的抗菌剂迫在眉睫. 以宿主防御肽及其模拟物为代表的多肽和聚合物近年来得到广泛关注. 而分子刷作为一类独特的聚合物也显示 了很多特殊的性能. 我们结合前期研究, 首次将两种开环聚合体系即 $\beta$-内酰胺开环聚合和 $\mathrm{N}$-羧基环内酸酐(NCA)开环聚合体系相结合, 以 $\beta$ 多肽为骨架结构进而通过其氨基功能基团进一步引发NCA开环聚合, 合成了侧链具有多个聚赖氨酸的 $\alpha / \beta$ 杂化多肽聚合物分子刷. 这种 新型分子刷对多种MRSA菌株均展现出高效的抗菌活性, 甚至优于万古霉素. 通过扫描电子显微镜(SEM)表征, 揭示了 $\alpha / \beta$ 杂化多肽聚合物 分子刷的抗菌机理与宿主防御肽类似, 是通过破坏细菌细胞膜的完整性杀菌. $\alpha / \beta$ 杂化多肽聚合物分子刷高度可调的结构特点和高效的抗 菌活性, 显示了其在抗菌研究和应用中的潜力. 